\title{
Evaluation of Fracture Resistance of Endodontic Treated Premolars Restored With Alkasite Restorative Materials: An in Vitro Study
}

\author{
Walaa M. Alsamolly ${ }^{* 1}$, Galal E. Sadek ${ }^{2}$, Tamer M. El-Shehawy ${ }^{3}$
}

Codex : 03/2021/10

Aadj@azhar.edu.eg

\section{KEYWORDS \\ (Cention- $N$ ), Activa bioactive, alkasite, fracture resistance, fracture mode.}

1. Department of Operative Dentistry, Faculty of Dental Medicine, (Cairo, Boys), Al-Azhar University, Egypt.

2. Department of Dental Bio-material, Faculty of Dental Medicine, ( Cairo, Boys), Al-Azhar University, Egypt.

3. Department of Operative Dentistry, Faculty of Dentistry, Mansoura University, Egypt

* Corresponding Author e-mail: Walsamolly @azhar.edu.eg

\begin{abstract}
Aim: This study aimed to compare the fracture resistance of endodontically treated premolars restored by Ceram x SphereTEC one composite resin, bioactive restorative material (ACTIVABioACTIVE Restorative), Alkasite restorative material (Cention-N) and Zirconia reinforced glass ionomer (Zirconomer). Subjects and Methods: Forty maxillary premolars were assigned into four equal groups according to the restorative material used . Group A: Teeth restored with Ceram x SphereTEC one. Group B: Teeth restored with ACTIVA BioACTIVE Restorative. Group C: Teeth restored with Cention-N and group D: Teeth restored with Zirconomer. Standardized flat MOD cavities after root canal treatment were prepared for all groups. Restorative materials were applied according to manufacture instructions. The teeth were mounted in universal testing machine and subjected to compressive force till fracture. Fracture patterns were evaluated under a stereomicroscope at magnification of $12 \times$. Data was statistically analyzed. Results: For all groups, the mean fracture resistance values were 1447.82 $\mathrm{N}, 1452.28 \mathrm{~N}, 1250.42 \mathrm{~N}$, and $920.39 \mathrm{~N}$, respectively. Statistical analyses showed no significant differences in the mean fracture resistances between group A, group B and group $C(p<0.05)$. There were significant differences between group $D$ and the other groups ( $p>0.05$ ). Conclusions: Ceram x SphereTEC one, Activa Bioactive Restorative and Cention- $\mathrm{N}$ have a high similar fracture resistances values in restoration of endodontically treated teeth, while Zirconomer has the lower value.
\end{abstract}

\section{INTRODUCTION}

Endodontically treated teeth are structurally compromised due to loose of structure caused by caries, wear, fractures and excessive removal of dentin during root canal treatment. These teeth are reduced in strength and increased cuspal fracture under occlusal load. ${ }^{(1)}$ The weakened teeth have to be restored with a proper restoration to strengthen the remaining teeth structure. Wherefore, successful of endodontically treated teeth depends on adequate root canal treatment as well as on adequate coronal restoration. ${ }^{(2)}$ 
Adhesive and composite are important in operative dentistry progression for endodontically treated teeth. ${ }^{(3)}$ Restoration of endodontically-treated teeth with coronal restoration is a final step for successful root canal treatment. Endodontically treated teeth are susceptible to fracture due to loss of water and massive loss of tooth structure. ${ }^{(4)}$

So, intra-coronal restoration is very important to strengthen the teeth especially posterior one to avoid fracture. ${ }^{(5,6)}$ Different restorative materials can be used after root canal treatment. Amalgam has high mechanical properties but it lacks adhesion with tooth structure that may cause cracking of tooth structure under masticatory load. ${ }^{(7)}$ Indirect restorations are very expensive and need multiple visits which may lead to incomplete treatment ${ }^{(8,9)}$.

Composite resin restorations ensure esthetically acceptable direct restorations that reinforce the strength of the endodontically treated teeth. ${ }^{(10)}$ Glass ionomer showed comparable mechanical strength to composite resin, but the strength of it deteriorates after 2 years. ${ }^{(11)}$

Recently, a new restorative material, Cention-N is introduced into the dental market. Cention- $\mathrm{N}$ is an "alkasite" restorative. ${ }^{(12)}$ Alkasite is a new category of filling material, which considers subgroup of composite material like compomer or ormocer materials. Cention- $\mathrm{N}$ is a direct tooth-coloured restoration. It is self-curing with optional additional light-curing. It is radiopaque, and releases fluoride, calcium and hydroxide ions. As a dual-cured material it can be used as a full volume (bulk) replacement material. ${ }^{(12)}$

A new class of restorative glass ionomer that comprises the strength and durability of amalgam is evolved as a recent posterior restorative material called Zirconomer. The inclusion of Zirconia fillers in glass component of Zirconomer reinforces the structural integrity of restoration and imparts superior mechanical properties in posterior load-bearing areas. ${ }^{(13)}$

Activa BioACTIVE is anew bioactive restorative material. Activa exchange ions between restoration and oral fluid. ${ }^{(14)}$ It contains silica glass particles, an ionic-based resin matrix, calcium, phosphate, and fluoride ions. ${ }^{(14)}$ The bioactivity improves durability, antimicrobial resistance, the chemical bond with dentin, and minimizes leakage due to oral contaminants. ${ }^{(15)}$

The present in vitro study will be undertaken to compare the fracture resistance of endodontically treated premolars restored by CERAM X SphereTEC one, ACTIVA BioACTIVE Restorative, Cention- $\mathrm{N}$ and Zirconomer .

\section{MATERIALS AND METHODS}

\section{Materials}

Detail description of the materials used in this study is listed in (Table 1).

Table (1) Restorative and Obturation materials used in the study

\begin{tabular}{|c|c|l|c|}
\hline $\begin{array}{c}\text { Material } \\
\text { Category }\end{array}$ & Brand Name & \multicolumn{1}{c|}{ Composition } & $\begin{array}{c}\text { Manufacture } \\
\text { and (Batch no) }\end{array}$ \\
\hline $\begin{array}{c}\text { Bioactive restor- } \\
\text { ative material }\end{array}$ & $\begin{array}{c}\text { ACTIVA BIOACTIVE } \\
\text { Restorative }\end{array}$ & $\begin{array}{l}\text { Blend of diurethane and other methacrylates } \\
\text { with modified polyacrylic acid. } \\
55.4 \mathrm{wt} \% \text { Bioactive glass and sodium fluoride }\end{array}$ & $\begin{array}{c}\text { Pulpdent. } \\
\text { Watertown, MA. } \\
\text { USA }\end{array}$ \\
\hline $\begin{array}{c}\text { Alkasite restorative } \\
\text { material }\end{array}$ & CENTION-N & $\begin{array}{l}\text { powder glass fillers (barium aluminium silicate glass filler, } \\
\text { ytterbium trifluoride, an Isofiller, a calcium barium alumin- } \\
\text { ium fluorosilicate glass filler and a calcium fluorosilicate } \\
\text { (alkaline) glass filler, initiator (Ivocerin) and pigments. } \\
\text { liquid dimethacrylates, initiators, stabilizer. }\end{array}$ & $\begin{array}{c}\text { Ivoclar Vivadent, } \\
\text { Schaan, Liehten- } \\
\text { stein. }\end{array}$ \\
\hline
\end{tabular}




\begin{tabular}{|c|c|c|c|}
\hline $\begin{array}{l}\text { Material } \\
\text { Category }\end{array}$ & Brand Name & Composition & $\begin{array}{c}\text { Manufacture } \\
\text { and (Batch no) }\end{array}$ \\
\hline $\begin{array}{l}\text { Bioactive restor- } \\
\text { ative material }\end{array}$ & Zirconomer & $\begin{array}{l}\text { Powder: Fluor aluminosilicate glass, zirconium oxide, } \\
\text { pigments and others. } \\
\text { Liquid: polyacrylic acid solution and tartaric acid. }\end{array}$ & $\begin{array}{l}\text { Shofu Inc., } \\
\text { Tokyo, Japan }\end{array}$ \\
\hline $\begin{array}{l}\text { Nano-hybridcom- } \\
\text { posite }\end{array}$ & $\begin{array}{l}\text { CERAM X } \\
\text { SphereTEC one,shade, } \\
\text { A3 }\end{array}$ & $\begin{array}{l}\text { Resin matrix: poly-urethane methacrylate, triethylenegly- } \\
\text { col dimethacrylate, highly dispersed and methacrylic poly- } \\
\text { siloxane nano-particles. } \\
\text { Filler system: blend of spherical, prepolymerized } \\
\text { SphereTEC }{ }^{\mathrm{TM}} \text { fillers, non-agglomerated barium glass and } \\
\text { ytterbium fluoride. filler load ranges from } 77-79 \text { weight- } \% \\
\text { total ( } 59-61 \% \text { by volume). }\end{array}$ & \multirow{2}{*}{$\begin{array}{l}\text { DENTSPLY IH } \\
\text { Ltd Building 3, } \\
\text { United Kingdom }\end{array}$} \\
\hline Universal adhesive & Prime\&Bondadhesive & $\begin{array}{l}\text { Bi- and multifunctional acrylate, phosphoric acid modified } \\
\text { acrylate resin, initiator, stabilizer, isopropanol and water. }\end{array}$ & \\
\hline Etching gel & Meta Etchant & $\begin{array}{l}\text { Non-dripping gel consistency, } 37 \% \text { phosphoric acid, Blue } \\
\text { color for visual control. }\end{array}$ & \\
\hline $\begin{array}{l}\text { Gutta percha } \\
\text { points }\end{array}$ & Root canal filling & Gutta percha, zinc oxide, barium sulfate, coloring agent & \\
\hline ADSEAL ${ }^{\mathrm{TM}}$ & Root canal sealer & $\begin{array}{l}\text { Base: Epoxy oligomer resin, Ethylene glycol salicylate, Cal- } \\
\text { cium phosphate, Bismuth subcarbonate, Zirconiumoxide. } \\
\text { Catalyst: poly aminobenzoate, triethanolamine, calcium } \\
\text { phosphate, bismuth subcarbonate, zirconium oxide, cal- } \\
\text { ciumoxide. }\end{array}$ & $\begin{array}{l}\text { META BIOMED } \\
\text { Co. LTD, Korea }\end{array}$ \\
\hline
\end{tabular}

\section{METHODS}

In this study forty sound human maxillary premolars extracted for orthodontic reasons, free from caries, defects or restorations were selected. All the teeth were vertically mounted in the center of Polyvinyl chloride (PVC) rings of $2 \times 2 \mathrm{~cm}$ size using an acrylic resin (Acrostone Cairo, Egypt) and fixed to $1 \mathrm{~mm}$ below the CEJ. Teeth were divided to four groups $(n=10)$ : Group A: CERAM X SphereTEC one, Group B: ACTIVA BIOACTIVE, Group C: CENTION-N and Group D: Zirconomer.

A standardized MOD cavity was prepared using straight fissure diamond instrument (Komet, Brasseler, Lemgo, Germany) in high speed hand-piece. Every five preparations, a new diamond instrument were changed. The dimensions of the cavity preparation were prepared without proximal steps. Buccolingual width of each cavity was one-third of the intercuspal distance at the occlusal portion and onethird of the bucco-lingual width of proximal boxes. The floor of the cavity was coronally prepared by 1 $\mathrm{mm}$ to the CEJ. The cavosurface margin was prepared ata butt joint. All the sharpness and internal line angles were rounded. An access cavity was prepared and canal orifices were enlarged with Gates Glidden drills .

The root canals were instrumented initially with \#10 and \#15 k-files (MANI Inc, Tochigi, Japan), then with rotary RaCe NI-TI system (FKG Dentaire SA, Switzerland) by technique of crown down. The canals were clinically instrumented till size \#35.04 taper for standardization purposes. The canals were irrigated and cleaned by using $3 \mathrm{ml}$ of $2.5 \% \mathrm{NaOCL}$ solution with 27-gauge endodontic needle after the use of each instrument. After canals dryness, thecanals were obturated with gutta-percha points using resin- based sealer (ADSEAL) with a cold lateral condensation technique. All prepared teeth were thoroughly cleaned with water and gently dried.

Then tofflemire metal matrix was applied, then the whole cavity was restored in accordance with themanufacturer's instructions as follow:-

Group A: CERAM X SphereTEC one group: The cavity was etched using Meta Etchant $37 \%$ phosphoric acid etching gel and bonded 
using Prime\&Bond adhesive, light cured for $15 \mathrm{~s}$, The teeth were built and filled with a CERAM X SphereTEC one resin composite. The whole cavity was incrementally restored and each increment was no more than $2 \mathrm{~mm}$ thickness and light cured for $20 \mathrm{~s}$.

Group B: Activa bioactive group: The cavity was conditioned for 10 seconds using Meta Etchant $37 \%$ phosphoric acid etching gel. The cavity was rinsed by water and air-dried. Activa restorative was inserted in the cavity in bulkand light cured for 20 seconds.

Group C: Cention-N alkasite group: The cavity was conditioned for 10 seconds using Meta Etchant $37 \%$ phosphoric acid etching gel. The cavity was rinsed and air-dried. The powder and liquid in the Cention- $\mathrm{N}$ was dispensed in a 1:1 ratio and mixed using a plastic spatula. The restoration was placed in the cavity in an increment and light cured for 20 seconds.

Group D: Zirconomer group: The cavity was conditioned for 10 seconds using Meta Etchant 37\% phosphoric acid etching gel. Washed and dried with gentle air flow. Zirconomer was mixed at specific powder to liquid ratio of 2:1 using glass slab and plastic spatula according to manufacturer instructions and placed in the cavity and adapted with condenser. The Zirconomer was self-cure after three minutes.

For all groups matrix band was removed, and occlusal surface was carved to an anatomic form.

Fracture resistance test:

After each restoration, the teeth specimens were stored in distilled water, to ensure complete polymerization, at $37 \pm 1^{\circ} \mathrm{C}$ at an incubator (WTC Binder, Tuttlingen, Germany ) for a duration of 48 hours before the fracture resistance testing, through the period of storage time the specimens were thermo cycled between $5{ }^{\circ} \mathrm{C}$ and $55{ }^{\circ} \mathrm{C}$ for 100 cycles (one minute for each) .Teeth were finished with fine diamond finishing instrument at low speed with oil free air-water spray, and polishing procedures were performed using Sof-lex discs(3M ESPE, ST. Paul, MN, USA). A Universal Testing Machine (Instron model 3345, UK) was used for measuring the force of fracture. A vertical compressive force was applied to the cusp slopes not to the restoration using ball tip $5 \mathrm{~mm}$ in radius, at a crosshead speed of 0.5 $\mathrm{mm} / \mathrm{min}$ until the force diagram showed a sudden fall. ${ }^{(16)}$ The maximum force was recorded in Newton as the fracture load. Data was recorded using computer software program BlueHill 3 software version 3.3 .

\section{Assessment of fracture mode:}

Magnifying lens was used to determine the fracture pattern. The fracture pattern was classified into adhesive, cohesive or mixed according to the fracture location. Adhesive fracture was considered when the fractureoccurred in the interface. Cohesive fracture was considered when the fracture occurred either in composite or toothstructure. Mixed fracture was considered when the fracture occurred in both cohesive and adhesive fracture pattern.

\section{Statistical Analysis:}

Data were tabulated and then analyzed statistically by using IBM SPSS software program (SPSS тм Software, V.20, IBM, NY, USA). Quantitative data were described using mean, standard deviation after testing normality using Kolmogorov-Smirnov test. Significance of the obtained results was judged at the 5\% level. One WayANOVA test: For normally quantitative variables, to compare between more than two groups with t- test to detect within groups significance.

\section{RESULTS}

\section{Results of Fracture Resistance Test}

Means of fracture strength and standard deviations for all groups are shown in (Table 2). A graphical presentation of these results is presented in (Figure 1). 
Table (2) Means of fracture strength and standard deviations of the adhesive systems.

\begin{tabular}{|c|c|c|c|c|}
\hline & $\mathrm{N}$ & $\begin{array}{c}\text { Means of fracture } \\
\text { strength }\end{array}$ & Standard deviations & Statisticaldifference \\
\hline CERAM X SphereTEC one & 10 & $1447.82 \mathrm{~N}$ & \pm 209.70 & \multirow{2}{*}{ A } \\
\hline ACTIVA BIOACTIVE & 10 & $1352.28 \mathrm{~N}$ & \pm 199.52 & \\
\hline CENTION-N & 10 & $1250.42 \mathrm{~N}$ & \pm 115.37 & \multirow{2}{*}{ A } \\
\hline Zirconomer & 10 & $920.39 \mathrm{~N}$ & \pm 144.42 & \\
\hline $\begin{array}{l}\text { ANOVA } \\
\text { p-value }\end{array}$ & & & $\begin{array}{l}\mathrm{F}=11.25 \\
\mathrm{p}<0.05^{*}\end{array}$ & B \\
\hline
\end{tabular}

Means followed by the same letters show no statistical differences $(p<0.05) . F$ : One Way ANOVA test

* statistically significant

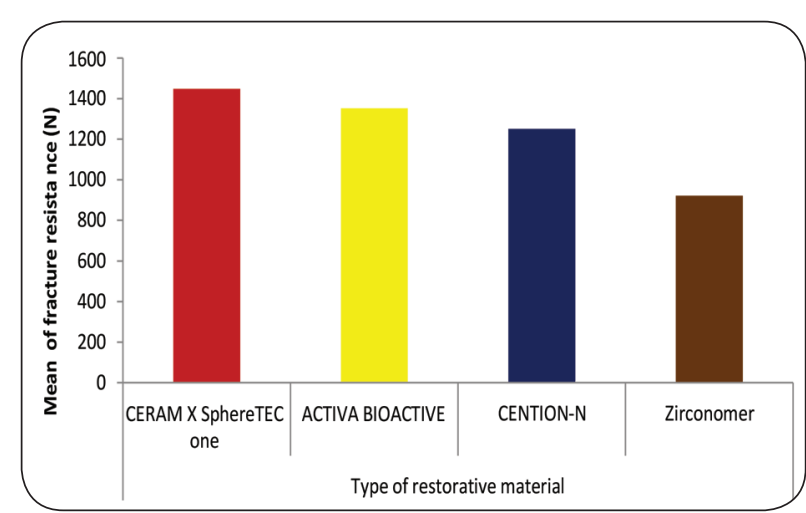

Fig. (1) Bar chart showing means fracture strength and standard deviations of studied restorative materials.

The one-way ANOVA results (Table 2) showed significant difference in fracture strength among restorative materials used $(\mathrm{p}<0.005)$. Comparing mean fracture strengths of all groups with different restorative material showed that Group1 restored with CERAM X SphereTEC one composite resin had the highest mean fracture resistance value $(1447.82 \pm 209.70 \mathrm{~N})$ while Group 4 restored with Zirconomer recorded the lowest mean value $(920.39 \pm 144.42 \mathrm{~N})$.

The results of Student t-test showed that there was a significant difference between fracture strength of Group1 restored with CERAM X SphereTEC one composite resin and Group 4 restored with Zirconomer, In addition there was a significant difference between fracture strength of
Group2 restored with a Bioactive activea and Group 4 restored with Zirconomer, also there was a significant difference between fracture strength of Group3 restored by Cention-N and Group 4 restored with Zirconomer.

On the other hand, no significant difference was found between Group1 restored with a CERAM X SphereTEC composite resin, Group2 restored by Activa Bioactive and Group3 restored by Cention-N

\section{Results of Fracture Patterns}

Results of failure mode distribution are illustrated in (Table 3) and (Figure 2). The mode of failure for Group1 restored with CERAM X sphere Tec one composite resin, was predominantly completefracture of the specimens involving cusps and restorative material (mixed), and followed by cohesive fracture of the tooth structure. For Group2 restored with a bioactive activea the mode of failure was predominantly mixed failure mode, followed by adhesive fracture at interface. For Group 3 restored by Cention- $\mathrm{N}$ the mode of failure was predominantly mixed failure mode of restorative material followed by cohesive failure. The mode of failure for Group 4 restored with Zirconomer was predominantly mixed failure mode followed by cohesive failure mode of restorative material. Different fracture patterns are presented in figure (3). 
Table (3) Distribution of fracture patterns observed for different adhesive systems.

\begin{tabular}{c|c|c|c|c}
\hline & CT & AD & MI & CR \\
\hline $\begin{array}{c}\text { CERAM X } \\
\text { SphereTECone }\end{array}$ & $20 \%$ & $20 \%$ & $50 \%$ & $10 \%$ \\
\hline $\begin{array}{c}\text { ACTIVA BIOAC- } \\
\text { TIVE }\end{array}$ & $20 \%$ & $30 \%$ & $40 \%$ & $10 \%$ \\
\hline CENTION-N & $20 \%$ & $30 \%$ & $40 \%$ & $10 \%$ \\
\hline Zirconomer & $20 \%$ & $40 \%$ & $30 \%$ & $10 \%$ \\
\hline
\end{tabular}

CT: Cohesive Failure in Tooth

$A D$ : Adhesive Failure

CR: Cohesive Failure in Restoration

MI: Mixed Failure

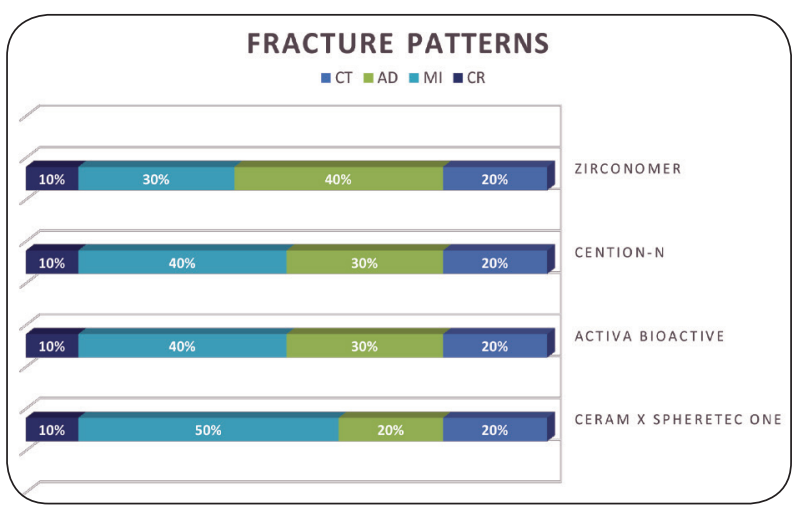

Fig. (2) Percentage values of fracture patterns of all groups.
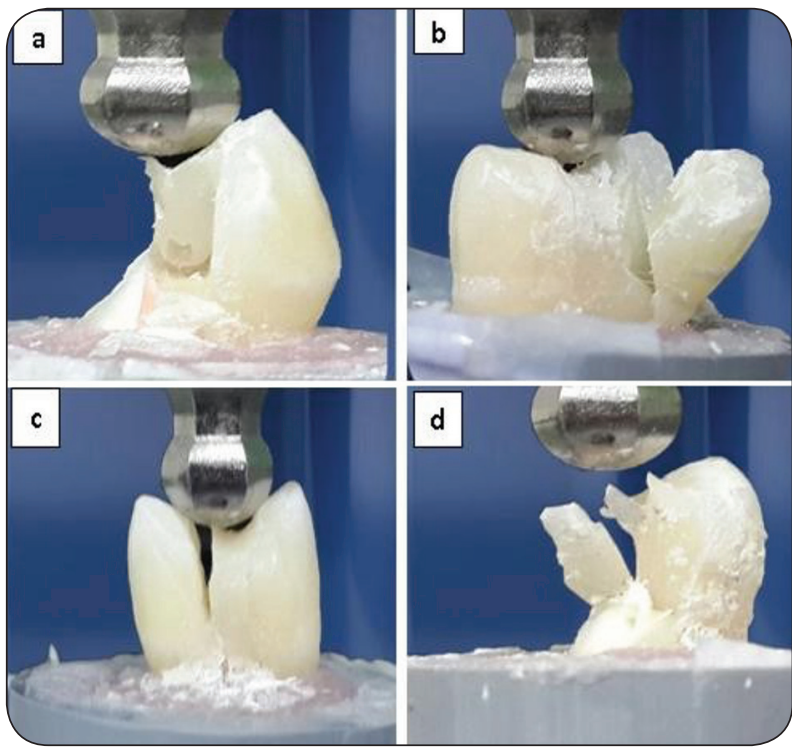

Fig. (3) Different fracture pattern; a-mixed failure, b- Cohesive failure of tooth structure, c-Adhesive failure and dCohesive failure of restoration.

\section{DISCUSSION}

Teeth with endodontic treatment are prone to fracture due to restorative procedures and brittleness that resulted from the extensive preparation and pulp removal. ${ }^{(17)}$ The effects of vitality loss on the physical properties of dentin have controversies. Some authors thought that the effect of vitality loss shows moderate to negligible concerning physical properties of dentin such as modulus of elasticity and micro hardness. ${ }^{(18,19,20)}$ Whereas others approved the extensive effects. ${ }^{(17,21,22)}$ The dentinal wall thickness is critical at the root circumference. There is a direct correlation between the ability of the tooth to resist intraoral forces and the root dentin diameter. (23) It has been shown that the teeth weakening due to endodontic and restorative procedures increases with the tooth structure reduction. ${ }^{(24)}$ Endodontic procedure reduces the tooth rigidity by $5 \%$, access cavity preparation shares in this reduction.

Marginal ridge loss is resulted in a loss of tooth rigidity, loss by $46 \%$ and $63 \%$ for compound and complex cavity, respectively. ${ }^{(25)}$ Other authors stated that unrestored tooth with MOD preparation was $50 \%$ less mean fracture strength than that of unaltered premolar teeth. ${ }^{(26)}$ MOD cavities were designed in this study to mimic a clinical situation that may often be seen in the clinic. The same situations have also been reproduced in other clinical studies.(27) For standardization, the cavity was prepared by using special diamond instruments and was fixed in a high-speed hand piece which attached to specially designed appliance in order to avoid incorrect interpretation and result. ${ }^{(28)}$

Among posterior teeth, specially maxillary premolars have unique morphology, position in the dental arch and cuspal inclination more susceptible to fracture under masticatory force. ${ }^{(29)}$ First premolar teeth were chosen in this study because restoration of premolars with resin composite considered more predictable than the molars. This concept was expected due to the lower polymerization stress caused by the smaller amount needed for 
composite restoration. ${ }^{(30)}$ In addition, premolars are more severe situation than molar teeth because of less crowns and dentinal surface for bonding. In this way, an extreme clinicalcondition was simulated. ${ }^{(30)}$

Each specimen was mounted on a Universal Testing machine subjected to compressive axial loading until fracture. The applied force speed was $0.5 \mathrm{~mm} /$ min. It was reported great plastic deformation occurred due to low speed giving higher fracture resistance measurements. ${ }^{(31)}$ The load direction (parallel to the long axis of the tooth) simulates physiological function. ${ }^{(32)}$ So the load was applied along the long axes to distribute stresses between the remaining tooth structure and the restorativematerial simulating a physiologic occlusion. ${ }^{(33)}$

Adhesive restorations have the ability to transmit the functional stresses through the restorative- tooth interface. ${ }^{(26)}$ Thus, the used restorations increase the fracture strength of the tooth and increase marginal sealing, and restore missing tooth structure. ${ }^{(34)}$

In the current study, four restorative materials were selected based on the chemical composition and fracture resistance was established. The current study showed that the CERAM X SphereTEC one resin composite produced higher fracture resistance values than other restorative materials, which are represented by Cention-N, Activa Bioactive and Zirconomer. The higher results of fracture resistance shown with CERAM X SphereTEC one can be explained by that it has nano hybrid spherical fillers, high filler content, high elastic modulus and slight deformation that are collected to provide unique adaptation to the tooth cavity walls that could contribute to more fracture resistance. ${ }^{(35)}$

Also, etching of dentin with phosphoric acid that causes a significant improvement of the interface morphology by forming a thicker hybrid, microretention layer. ${ }^{(36)}$ In this case, phosphoric acid etching removes smear layer and their plug resulted in opening the dentinal tubules and permitting resin tags infiltration and anastomosis, thus increasing hybridization and bonding of resin composite to tooth structure. ${ }^{(37,38)}$ Moreover, phosphoric acid etching of enamel increases their surface tension, makes a high surface energy and leads to very strong bond. ${ }^{(39)}$

Composite resin has been set as the gold standard for core build-up material. The fracture resistance of composite resin according to our study was $1447 \mathrm{~N}$, which is comparable to various previous studies showing $1407 \mathrm{~N}$ and $1499 \mathrm{~N} .{ }^{(40,41)}$ the main disadvantage of composite resin is the technique sensitivity and difficult manipulation. ${ }^{(42)}$

Activa bioactive restorative recorded higher fracture resistance values than Cention-N. This finding is agreeing with previous studies ${ }^{(43,44)}$, which found that ACTIVA was significantly superior to different commercial types of RMGI regarding the mechanical properties.

Mechanical properties are affected by monomer composition of the polymer based restorative materials ${ }^{(45)}$. Bis-GMA (Biphenyl-A glycidyl-methacrylate) is composed of an epoxy resin and methyl methacrylate and used as a matrix resin. This composition increases the viscosity and rigidity of the $\operatorname{resin}^{(46)}$. Urethane-dimethacrylates (UDMA) has high flexibility higher molecular weight and low viscosity, resulting in higher flexural strength. Studies reported that flexural strength increases when Bis GMA or TEGDMA are substituted by UDMA ${ }^{(47)}$.

Monomers of Activa are a mixture of UDMA a shock-absorbing resin component with other methacrylate and reactive ionomer glass ${ }^{(43)}$. This explained that Activa exhibits high resilience of ACTIVA against impact forces and better mechanical and physical properties Compared to RMGIs. ${ }^{(43)}$

Cention-N Is an alkasite restorative material used in retentive cavity with or without adhesion. ${ }^{(48)}$ Cention-N gave a reading of $1319 \mathrm{~N}$ which was comparable to composite resin. The high strength of alkasite cement Cention- $\mathrm{N}$ is attributed to the high filler contents and the polymerization reaction. Bariumaluminum silicate glass and calcium 
aluminum silicate glass are the fillers that render strength to the material. The flexural strength of Cention- $\mathrm{N}$ is $>110 \mathrm{MPa}$ which makes it more suitable and a long-lastingmaterial in the stress-bearing posterior region. ${ }^{(49,50)}$

Cention $-\mathrm{N}$ has a high density polymer network and high depth of cure due to the use of cross- linking methacrylate monomers in combination with self-cure initiator. ${ }^{(50)}$ It has low polymerization stresses due to the presence of isofiller and low elastic modulus which act as stress reliever. ${ }^{(50)}$

This is in agreement with Chowdhury, D. et $\mathrm{al}^{(51)}$. Were evaluated the fracture resistance of two advanced restorative materials, Z350 Nano fill composite resin and Cention-N in a class II cavity with routinely used silver amalgam material. It was concluded that the use of Cention-N and Z350 restorative materials significantly strengthen teeth after Class II cavity preparation and restoration ${ }^{(51)}$.

Zirconomer is zirconia reinforced glass ionomer cement, which the manufacturer claims to display superior mechanical properties while maintaining the capacity for release of fluoride of GICs ${ }^{(52)}$.

According to the Zirconomer (white amalgam) company, it exhibits strength consistent with amalgam and is more esthetically acceptable. In order to attain optimum particle size and characteristics, the glass components of this high-resistance ionomer undergoes fine controlled micronization. ${ }^{(53)}$

Zirconia particles have been homogenously incorporated into the glass element to further strengthen the material for long lasting durability and high tolerance to occlusal load. Polyalkenic acid and glass elements were also specially processed to convey to this high-strength glass ionomer superior mechanical qualities. ${ }^{(53-54)}$

\section{CONCLUSIONS}

Within the limitations of this study, it can be concluded that composite resin restoration is the ideal material for core buildup. However, Activa bioactive and Cention $\mathrm{N}$ have shown equally good results. Due to the easier manipulation of Activa bioactive and Cention $\mathrm{N}$ compared to composite resin, it can be used as an alternative for core build-up material in clinical practice.

\section{REFERENCES}

1. Mannocci F, Bertelli E, Sherriff M, Watson TF, Pitt Ford T. Three-year clinical comparison of survival of endodontically treated teeth restored with either full cast coverage or with direct composite restoration. Int Endod J 2009;42:401-405.

2. Gillen BM, Looney SW, Gu L-S, Loushine BA, Weller $\mathrm{RN}$, Loushine RJ, et al. Impact of the quality of coronal restoration versus the quality of root canal fillings on success of root canal treatment: a systematic review and meta-analysis. J Endod 2011;37:895-902.

3. Gisovar FE, Hedayati N, Shadman N, Shafiee L. Comparing the shear bond strength of six adhesive systems to enamel of primary teeth. J Dent 2014;4:1-3.

4. Belli S, Erdemir A, Yildirim C. Reinforcement effect of polyethylene fibre in root filled teeth: Comparison of two restoration techniques. Int Endod J. 2006;39:136-142.

5. Hürmüzlü F, Serper A, Siso SH, Er K. In vitro fracture resistance of root filled teeth using new generation dentine bonding adhesives. Int Endod J. 2003;36:770-773.

6. Daneshkazemi AR. Resistance of bonded composite restorations to fracture of endodontically treated teeth. J Contemp Dent Pract. 2004;5:51-58.

7. Soares PV, Santos-Filho PC, Gomide HA, Araujo CA, Martins LR, Soares CJ. Influence of restorative technique on the biomechanical behavior of endodontically treated maxillary premolars. Part 11: Strain measurement and stress distribution. J Prosthet Dent. 2008;99:114-122.

8. Siso SH, Hürmüzlü F, Turgut M, Altundaşar E, Serper A, Er K. Fracture resistance of the buccal cusps of root filled maxillary premolar teeth restored with various techniques. Int Endod J. 2007;40:161-168.

9. Sedgley CM, Messer HH. Are endodontically treated teeth more brittle? Int Endod J. 1992;18:332-335.

10. Santos MJ, Bezerra RB. Fracture resistance of maxillary premolars restored with direct and indirect adhesive techniques. J Can Dent Assoc 2005;71:585 
11. Mincik J, Urban D, Timkova S, Urban R. Fracture resistance of endodontically treated maxillary premolars restored by various direct filling materials: An in vitro study. Int J Biomater 2016;2016:9138945

12. Scientific documentation: Cention-N. Schaan, Liechtenstein: Ivoclar Vivadent press; 2016, pp 1-58

13. 13-Patel MU, Punia SK, Bhat S and Singh G. An in vitro evaluation of microleakage of posterior teeth restored with amalgam, composite and Zirconomer. J ClinDiagn Res 2015; 9: 65-7.

14. Pulpdent. ACTIVA BioACTIVE [white paper]. 3rd ed, https://www.pulpdent.com/wp- content/uploads/2015/12/ ACTIVA-White-Paper-XF-VWP6-REV-06-2017-3.pdf (June 2017, accessed19 August 2019).

15. Owens BM, Phebus JG and Johnson WW. Evaluation of the marginal integrity of a bioactive

16. Naves LZ, Silva GRd, Correr-Sobrinho L, Costa AR, Valdivia ADCM, Soares CJ. Influence of crosshead speed on failure load and failure mode of restored maxillary premolars. Braz Oral Res 2016;30:1806-1807.

17. Soares PV, Santos-Filho PCF, Queiroz EC, Araújo TC, Campos RE, Araújo CA, et al. Fracture resistance and stress distribution in endodontically treated maxillary premolars restored with composite resin.J Prosthodont 2008;17:114-119.

18. Dimitriu B, Vârlan C, Suciu I, Vârlan V, Bodnar D. Current considerations concerning endodontically treated teeth: alteration of hard dental tissues and biomechanical properties following endodontic therapy. J Med Life 2009;2:60-65.

19. Shivanna V, Gopeshetti PB. Fracture resistance of endodontically treated teeth restored with composite resin reinforced with polyethylene fibres. Endodontology 2013;24:73-79.

20. Dietschi D, Duc O, Krejci I, Sadan A. Biomechanical considerations for the restoration of endodontically treated teeth: a systematic review of the literature-Part 1. Composition and micro-and macrostructure alterations. Quintessence Int 2007;38:733-743.

21. Mortazavi V, Fathi M, Katiraei N, Shahnaseri S, Badrian $\mathrm{H}$, Khalighinejad N. Fracture resistance of structurally compromised and normal endodontically treated teeth restored with different post systems: An in vitro study. Dent Res J 2012;9:185-191
22. Sharafeddin F, Alavi AA, Zare S. Fracture resistance of structurally compromised premolar roots restored with single and accessory glass or quartz fiber posts. Dent Res J 2014;11:264-271.

23. Hürmüzlü F, Kiremitci A, Serper A, Altundaşar E, Sİso ŞH. Fracture resistance of endodontically treated premolars restored with ormocer and packable composite. J Endod 2003;29:838-840.

24. Soares PV, Santos-Filho PCF, Gomide HA, Araujo CA, Martins LRM, Soares CJ. Influence of restorative technique on the biomechanical behavior of endodontically treated maxillary premolars.: Part II: Strain measurement and stress distribution. J Prosthet Dent 2008;99:114-122.

25. Plotino G, Buono L, Grande NM, Lamorgese V, Somma F. Fracture resistance of endodontically treated molars restored with extensive composite resin restorations. J Prosthet Dent 2008;99:225-232.

26. Jiang W, Bo H, Yongchun G, LongXing N. Stress distribution in molars restored with inlays or onlays with or without endodontic treatment: a three-dimensional finite element analysis. J Prosthet Dent 2010;103:6-12.

27. Sagsen B, Aslan B. Effect of bonded restorations on the fracture resistance of root filled teeth. Int Endod J 2006;39:900-904.

28. Soares CJ, Fonseca RB, Gomide HA, Correr-Sobrinho L. Cavity preparation machine for the standardization of in vitro preparations. Braz Oral Res 2008;22:281-287.

29. Wu M-K, Van Der Sluis L, Wesselink P. Comparison of mandibular premolars and canines with respectto their resistance to vertical root fracture. J Dent 2004;32:265-268.

30. Sengun A, Cobankara FK, Orucoglu H. Effect of a new restoration technique on fracture resistance of endodontically treated teeth. Dent Traumatol 2008;24:214-219.

31. Siso Ş, Hürmüzlü F, Turgut $M$, Altundaşar E, Serper A, Er K. Fracture resistance of the buccal cusps of root filled maxillary premolar teeth restored with various techniques. Int Endod J 2007;40:161-168.

32. Salameh Z, Sorrentino R, Papacchini F, Ounsi HF, Tashkandi E, Goracci C, et al. Fracture resistance andfailure patterns of endodontically treated mandibular molars restored using resin composite with or without translucent glass fiber posts. J Endod 2006;32:752-755.

33. Sorrentino R, Salameh Z, Zarone F, Tay FR, Ferrari M. Effect of post-retained composite restoration of MOD preparations on the fracture resistance of endodontically treated teeth. J Adhes Dent 2007;9:49-56. 
34. McLeod ME, Price RB, Felix CM. Effect of configuration factor on shear bond strengths of self-etch adhesive systems to ground enamel and dentin. Oper Dent 2010;35:84-93.

35. Anil K Tomer, Dr. Afnan Ajaz Raina, Dr. Faizan Bin Ayub, Dr. Akankshita Behera, Dr. Nitish Mittal, Dr. Sneha Vaidya, Dr. Midhun Ramachandran and Dr. Ashvin G John Fracture strength of composite veneers using different restorative materials: A comparative in vitro study international Journal of Applied Dental Sciences 2017; 3: 465-468

36. Ceballos L, Camejo DG, Fuentes MV, Osorio R, Toledano M, Carvalho RM, et al. Microtensile bond strength of total-etch and self-etching adhesives to caries-affected dentine. J Dent 2003;31:469-477.

37. Scholtanus J, Purwanta K, Dogan N, Kleverlaan CJ, Felizer AJ. Microtensile bond strength of threesimplified adhesive systems to caries-affected dentin. J Adhes Dent 2010;12:273-278.

38. Tekçe N, Demirci M, Tuncer S, Uysal Ö. Effect of different application techniques of all-in-oneadhesives on microtensile bond strength to sound and cariesaffected dentin. J Adhes 2015;91:245-261.

39. Sengun A, Orucoglu H, Ipekdal I, Ozer F. Adhesion of two bonding systems to air-abraded or bur-abraded human enamel surfaces. Eur J Dent 2008;2:167-175.

40. Ragauska A, Apse P, Kasjanovs V, Berzina-Cimdina L. Influence of ceramic inlays and composite fillings on fracture resistance of premolars in vitro. Stomatologija 2008;10:121-126.

41. Panahandeh N, Johar N. Effect of different cusp coverage patterns on fracture resistance of maxillary premolar teeth in MOD composite restorations. J Islam Dent Assoc Iran 2014;25:228-232.

42. Alhareky M, Tavares M. Amalgam vs. composite restoration, survival, and secondary caries. J Evid Based Dent Pract 2016;16:107-109.

43. Pameijer CH, Garcia-Godoy F, Morrow BR, Jefferies SR. Flexural strength and flexural fatigue properties of resinmodified glass ionomers. J Clin Dent 2015;26:23-27.
44. Croll TP, Berg JH, Donly KJ. Dental repair material: a resin-modified glass-ionomer bioactive ionic resin-based composite. Compend Contin Educ Dent 2015;36:60-65.

45. Asmussen E, Peutzfeldt A. Influence of UEDMA, BisGMA and TEGDMA on selected mechanical properties of experimental resin composites. Dent Mater 1998;14:51-56.

46. Floyd CJ, Dickens SH. Network structure of Bis-GMAand UDMA-based resin systems. Dent Mater 2006; 22 : 1143-1149.

47. Ogliari FA, Ely C, Zanchi CH, Fortes CB, Samuel SM,Demarco FF, Petzhold CL, Piva E. Influence of chain extender length of aromatic dimethacrylates on polymer network development. Dent Mater 2008;24:165-171.

48. Ende, A. V., Munck, J. D., Lise, D.P., Meerbeek, B.V. Bulk fill composites: A review of the current literature. $J$ Adhes Dent 2017; 19: 95-109.

49. Samanta, S., Das, U.K., Mitra, A. 2017. Comparison of microleakage in class $\mathrm{V}$ cavity restored with flowable composite resin, glass ionomer cement and Cention-N. Imp J Interdiscip Res 2017; 8: 180-83.

50. Samanta S, Das UK, Mitra A. Comparison of micro leakage in class $\mathrm{V}$ cavity restored with flowable composite resin, glass ionomer cement and Cention-N. Imp J Interdiscip Res 2017;1:3.

51. Chowdhury, D., Guha, C., Desai, P. Comparative Evaluation of Fracture Resistance of Dental Amalgam, Z350 Composite Resin and Cention-N Restoration In Class II Cavity: J Dent Med Sci 2018;17:52-56.

52. http://www.shofu.com.sg/downloads/pdf/Zirconomer $\% 20$ Brochure.pdf.

53. Haragopal S, Sreeramulu B, Shalini K, Sudha MD, Kiran G. Zirconia: A credible restorative material-A review. Ann Essences Dent 2012;4:63-65.

54. Chalissery VP, Marwah N, Almuhaiza M, AlZailai AM, Chalisserry EP, Bhandi SH, et al. Study of the mechanical properties of the novel zirconia-reinforced glass lonomer cement. J Contemp Dent Pract 2016;17:394-398. 
مجلة أسيوط لطب الأسنان

النشر الرسمي لكلية طب الأسنان جامعة الأزهر أسيوط الكاية

مصر

AADJ, Vol. 4, No. 2, October (2021) - PP. 127

ولاء محمد أحمد السمولي *1, جالال الدين صادق2 , تامر محمد الشهاوي3

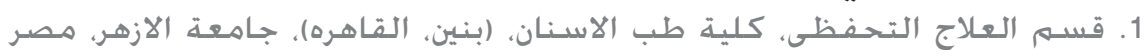

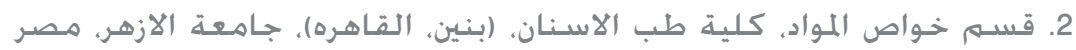

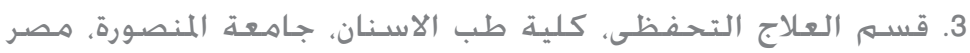

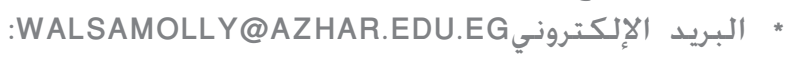

(الملخص:

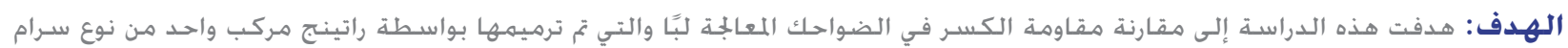

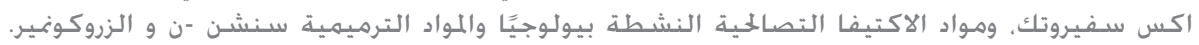

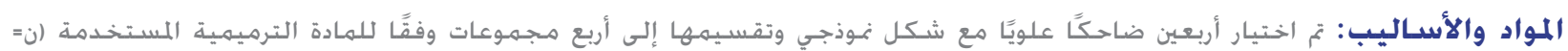

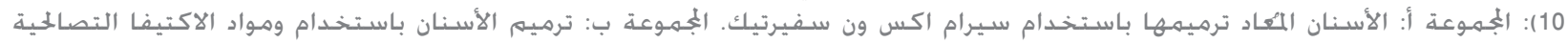

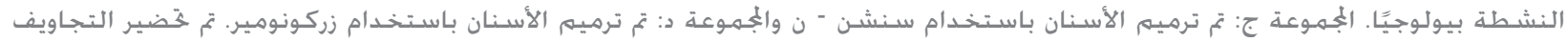

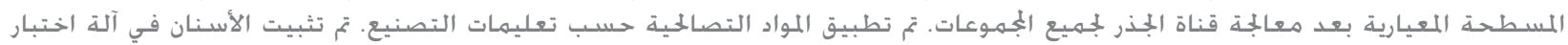

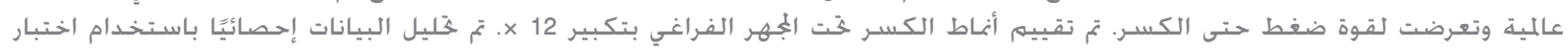

النتائج: بالنسبة لجمهوعات العلاج الأربعة، كانت نتائج متوسط قئهم مقاومة الكسـر

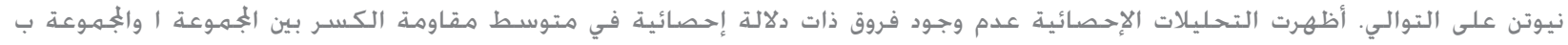

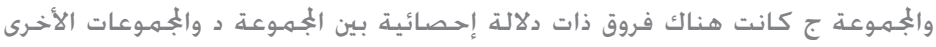

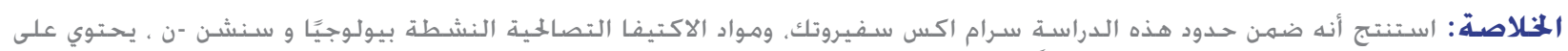

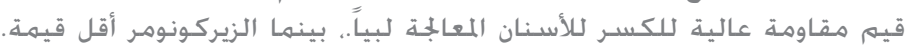
الكسلمات المفتاحية: سـشـن -ن، ومواد الاكتيفا التصالحية النشطة بيولوجيًا، الكيسـات، مقاومة الكسر، نمط الكسـر 